\title{
Research on incentive mechanism of scientific and technological talents in high-tech industry
}

\author{
Zhao Yan ${ }^{1}$ \\ ${ }^{1}$ Shan Dong Institute of Commerce and Technology, Ji Nan, China
}

\begin{abstract}
In the era of intelligent economy, scientific and technological talents have become the key objects of staff incentives in high-tech industries, but the actual effect of scientific and technological talents incentive is not optimistic, mainly manifested in the generally low incentive satisfaction of scientific and technological talents. The main reason for the above problems is that the incentive mechanism of scientific and technological talents in high-tech industry is not reasonable. In view of the problems existing in the incentive mechanism of scientific and technological talents, a new incentive mechanism of scientific and technological talents is constructed by integrating the ideas and methods of human capital theory, behavioral science and incentive theory. Combining the value-added of financial capital of high-tech enterprises with the ability, contribution, behavior and effort of scientific and technological talents, we can fundamentally stimulate the enthusiasm, initiative and creativity of scientific and technological talents.
\end{abstract}

\section{Research background and issues raised}

In the era of intelligent economy, the importance of scientific and technological talents is increasingly prominent, especially in the high-tech industry. How to establish an effective incentive mechanism for scientific and technological talents and stimulate the endogenous power of scientific and technological talents has become the core issue that must be considered in the high-tech industry. Countries attach great importance to the cultivation and incentive of scientific and technological talents, and have issued a series of documents to

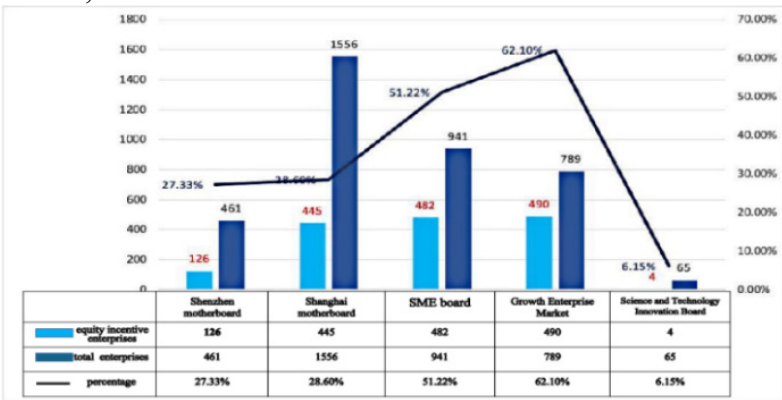

Fig1. equity incentive of science and technology talents of chinese listed companies in 2019

guide the practice of enterprises, generally adopting the incentive mode of equity. In China, for example, nearly $40 \%$ of listed companies have implemented equity incentive plans for scientific and technological talents. In the Growth Enterprise Market dominated by high-tech enterprises, the implementation proportion is as high as $62 \%$, as shown in figure $1[1]$. However, the actual effect of scientific and technological talents incentive in high- tech industry is not optimistic, which is mainly reflected in the low incentive satisfaction of scientific and technological talents. Take China as an example, the job satisfaction of scientific and technological talents in hightech industry is less than $60 \%$, and the life satisfaction is less than $50 \%$, as shown in figure 2[2]. Even Microsoft, Google and other world-famous technology companies are not satisfied with the satisfaction of technological talents, which were $65 \%$ and $64 \%$ in $2017,61 \%$ and $54 \%$ in 2018. The main reasons for the above

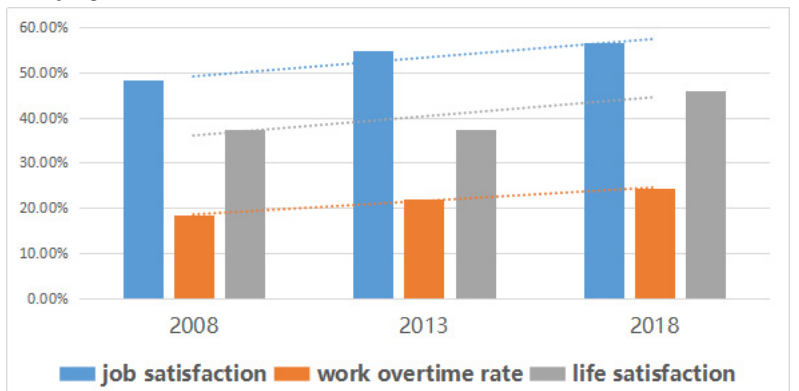

Fig2. job and life satisfaction of science and technology talents in chinese high-tech industry

problems are the lack of strategic awareness and unreasonable incentive mechanism, especially the defects of the current equity incentive policy in high-tech industry. First of all, the current equity incentive policies mostly adopt the ways of capital expansion, new investment and other ways, rather than take human resources, capacity, contribution to become a shareholder, as shown in figure 3 and figure 4 . The capital-based way of becoming a shareholder has not been fully linked with the ability of scientific and technological talents, and some qualified talents may even be unable to become a shareholder if they have not enough money. Secondly, the residual income of 
the enterprise after becoming a shareholder is allocated according to the initial shareholding share of scientific and technological talents, rather than the value created by talents. The income of scientific and technological talents cannot be effectively linked with their ability, contribution and performance, which frustrates the enthusiasm, initiative and creativity of scientific and technological talents and fails to realize long-term incentive and constraint, thus causing the behavior of scientific and technological talents to deviate greatly from the expectation of enterprises.

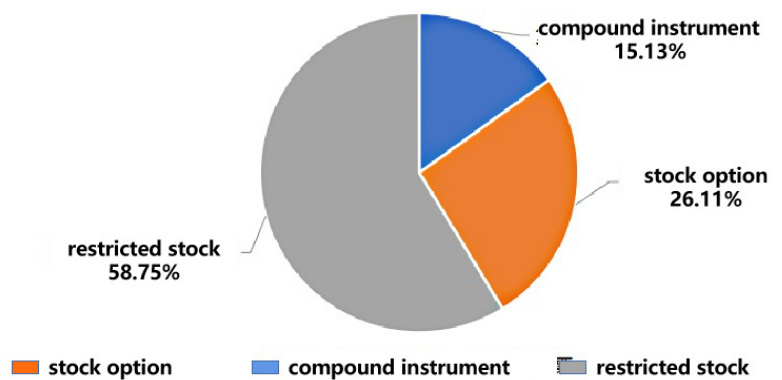

Fig3. selection of equity incentive tools for listed companies in chinese high-tech industry in 2019

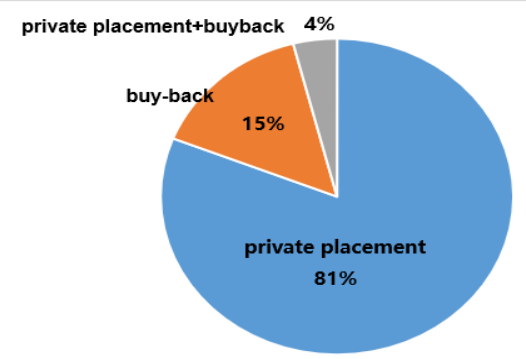

- private placement $\equiv$ buy-back $=$ private placement+buyback

Fig4. sources of equity incentive shares of listed companies in chinese high-tech industry in 2019

In view of the problems existing in the incentive mechanism of scientific and technological talents in hightech industry (hereinafter referred to as "scientific and technological talents"), this study constructs a new incentive mechanism of scientific and technological talents based on human capital theory, behavioral science theory, incentive theory, etc. First of all, human capital is introduced into the equity incentive of scientific and technological talents. On this basis, the dynamic measurement of behavior contribution and the dynamic adjustment mechanism of equity are established, that is, the value-added of financial capital of enterprises is combined with the ability, contribution, behavior and effort of scientific and technological talents. At the same time, the transfer mechanism and exit mechanism of human capital equity of scientific and technological talents are established. Through the above measures, we can fundamentally stimulate the enthusiasm, initiative and creativity of scientific and technological talents.

\section{Theoretical basis of research}

\subsection{Human capital theory}

T.W.Schultz, the founder of human capital theory and the Nobel Prize winner in 1979, thinks that human capital is the sum of knowledge, skills and physical value with economic value existing in human body. It is a kind of capital juxtaposed with material capital, and human capital investment is the main source of economic growth. He used a lot of experience materials to prove that in the process of economic modernization, the economic importance of physical capital is declining, and the importance of skills and knowledge is increasing. After Schultz, many scholars, such as Gary. S. Becker, analyzed the significant impact of human capital investment on employment income and its contribution to economic growth. Up to now, human capital has become a recognized capital form. According to the theory of human capital, human capital is an important part of enterprise capital, just like material capital such as land and currency. Workers are the owners of human capital. In the process of economic activities or value creation, only when material capital is combined with human capital can value be created. After the enterprise obtains the human capital of the laborer, in addition to paying the labor compensation value of the laborer such as salary, it should arrange the owners of the human capital and the owners of the material capital to participate in the sharing of the surplus income according to the principle of "who invests, who benefits".

\subsection{Property right theory}

Property right refers to the right of a certain economic subject to own, use, dispose of and obtain corresponding income from a specific economic object according to law. The subject of property right can independently exercise all the rights to the assets, transfer them, and gain profits. The human capital owned by the laborer accords with all the connotation of property right, which is a special property right owned by the laborer. The property right of laborer is the same as the property right of material capital, so we should maintain and increase the value of property. Maintenance of value is the compensation of capital consumption for physical capital, such as depreciation of fixed assets; for human capital, it is the compensation of labor consumption, such as wages. Value added refers to the sharing of residual income between the two sides. After the scientific and technological talents are invested in human capital, they can share the residual income of the enterprise as the owner, and the value of the human capital of the scientific and technological talents can be fully realized, so as to further stimulate the initiative and enthusiasm of the scientific and technological talents and promote the development of the enterprise.

\subsection{Incentive theory}

According to the theory of motivation, the most effective way of motivation is internal motivation, that is, self 
motivation. After scientific and technological talents take human capital as shares, they are both employees and owners of the enterprise. The development of the enterprise is closely connected with the interests of the scientific and technological talents. This kind of incentive is a typical internal incentive, which belongs to the initiative and positive self incentive of the scientific and technological talents. This move has successfully transformed the traditional "principal-agent" relationship into "principal-agent-self-care" relationship, which can produce the most effective long-term effect, meet the longterm interests of enterprises and talents, and is conducive to the sustainable development of enterprises and talents.

\subsection{Behavioral science theory}

Behavioral science is a science that regards human and behavior in the system as the research object. Behavioral science mainly uses the research results of sociology, psychology, anthropology and physiology to study the regularity of human behavior, analyze the causes and influencing factors of people's various behaviors, and study how to arrange the organizational environment and risk management, so as to predict, control and motivate people's behaviors, so as to promote the behaviors we want to appear frequently and suppress the behaviors we don't want. The research of behavioral science includes four aspects: the research of human needs and motivation; the research of human nature; the research of informal groups and human relationship in enterprises; the research of leadership style, etc. Based on the research of motivation of behavior science, this paper focuses on the problem of behavior measurement and behavior optimization.

\section{The mechanism design of human capital's share of science and technology talents in high-tech industry}

The definition of human capital can be summed up into two points: one is to regard human capital as the skills formed by education investment; the other is to discuss the ownership of human capital from the perspective of property rights, and regard it as the capital owned by workers. In fact, human capital can create economic value. After recognizing the value of human capital, the capital of an enterprise can be divided into two forms: one is material capital, such as land, money, machinery and equipment; and the other is human capital. The investment of human capital into shares refers to that workers invest in shares with their own human capital value and share profits and losses according to their shares.

The human capital of scientific and technological talents can only be invested in high-tech enterprises after evaluation, and then they can share the profits and losses and bear the responsibilities according to the number of shares they hold. After the human capital is invested, the scientific and technological talents are both shareholders and employees. The scientific and technological talents closely link their own interests with the enterprise interests, which is conducive to mobilizing the enthusiasm of the scientific and technological talents.

3.1.1 Methods of evaluation. We can learn from the evaluation method of human resource value in human resource accounting. In human resource accounting, there has been a human resource value evaluation system with monetary measurement as the main and non monetary measurement as the auxiliary. The quantitative model is adopted in monetary measurement, mainly including future wage discount method, random return method, economic value method, future net asset discount method, etc. Non monetary measurement introduces the principles and measurement models of other disciplines, and adopts the comprehensive evaluation of work attitude, ability and performance. The main methods are behavioral scientific variable method, behavioral matrix method, fuzzy comprehensive evaluation method, etc. Although the above methods have advantages and disadvantages, they provide reference for the evaluation of human resource value of scientific and technological talents.

3.1.2 Evaluation agency. The human capital of scientific and technological talents can be valued by the legal evaluation institution or by all shareholders through consultation. If the appraisal price is determined, the appraisal certificate of the legal appraisal institution shall be provided; if the appraisal price is determined through consultation, the agreement reached by all shareholders on human capital's share participation shall be provided. After the shares are acquired, the shares held by scientific and technological talents is not unchangeable. High-tech enterprises need to reevaluate the human capital of scientific and technological talents on a regular basis according to their contributions.

\section{The design of measurement mechanism of behavior contribution and dynamic adjustment mechanism of stock rights of scientific and technological talents in high-tech industry}

\subsection{Design of measurement mechanism for behavior contribution of scientific and technological talents}

The performance measurement of scientific and technological talents is redesigned with behavior as the main line. Through the design of measurement mode and the implementation of measurement behavior, the behavior of scientific and technological talents is influenced, which effectively guides scientific and technological talents to achieve organizational and personal goals. In the specific measurement, we should adhere to the following concepts: first, quantification is the main factor and uncertainty is allowed. Due to the complexity of behavior, it is impossible to measure it accurately, as long as stakeholders agree. Second, behavior measurement should be corresponding to each actor, and the factors that affect the correctness of behavior should be included in the measurement category. New Liberalism Economics of the United States proposes that 
everyone can be an enterprise, because everyone has their own available resources and pursuit goals, and they all want to achieve the largest input-output ratio possible. This idea will be introduced into the behavior measurement of scientific and technological talents, the factors that affect the correctness of behavior will be included in the measurement category, and the behavior measurement will be implemented to individuals, so as to influence and optimize the behavior of each behavior subject.

The basic framework of the measurement of the behavior contribution of scientific and technological talents. The measurement of the behavior contribution of scientific and technological talents can be divided into three stages: before, during and after.

4.1.1 In advance, analyze the behavior process and establish the behavior indicators and standards. According to cybernetics, behavioral analysis and performance management theory, behavioral indicators are designed, which can be composed of time, quantity, quality and value. Time index refers to the time limit required for the implementation of the act. Quantity and quality index refer to the quality and quantity standards of products and services caused by the act. Value index refers to the amount of changes in the economic value of the enterprise caused by the act. Set behavioral standards, in which the current market price is selected for the setting of value standards and adjusted in real time according to market conditions; the setting of time, quantity and quality standards is based on the actual needs of high-tech enterprises.

4.1.2 In the process, the behavior process is measured according to the set behavior indicators and standards. The measurement of behavior process includes three situations: reaching behavior standard, surpassing behavior standard or inferior to behavior standard. For those who meet the standards of conduct, the prescribed remuneration and income shall be given. For those who are superior to the standards of conduct, the income of conduct value shall be recognized after quantitative treatment; for those who are inferior to the standards of conduct, the loss of conduct value shall be recognized after quantitative treatment.

4.1.3 Afterwards, the behavior contribution of scientific and technological talents is calculated.

The behavior contribution of scientific and technological talents $=$ prescribed reward and income + behavior value income- behavior value loss.

\subsection{Design of dynamic adjustment mechanism of human capital equity of scientific and technological talents}

According to the behavior contribution of scientific and technological talents, the high-tech enterprises distribute the income, and dynamically adjust the shares held by employees. Human capital varies with the change of the ability and contribution of scientific and technological talents, that is, human capital increases with the increase of human resource contribution and decreases with the decrease of human resource contribution. In addition, enterprises should evaluate the behavior performance of scientific and technological talents according to their behavior contribution, so as to promote the improvement of their behavior.

\section{The design of profit distribution mechanism of scientific and technological talents in high-tech industry}

\subsection{Revenue sharing mechanism}

After science and technology talents take human capital as shares, they will form the owner's equity of high-tech enterprises together with material capital. Scientific and technological talents can share the surplus income of the enterprise with the owners of material capital while obtaining the income of labor compensation such as wages As mentioned before, the share of human capital is not the same after it is invested, but is revalued regularly according to the ability and contribution of scientific and technological talents. Therefore, the surplus income shared by scientific and technological talents is also in dynamic adjustment, which is closely related to the behavior contribution of scientific and technological talents.

How to determine the income distribution ratio between material capital and human capital of scientific and technological talents. This paper holds that the proportion is determined by the full game between the two sides. It is generally believed that when the enterprise's return rate is higher than the social average return rate, the scientific and technological talents should share more profits brought about by excess labor or creative labor; while when the enterprise's return rate is lower than the social average return rate, the material capital should share more profits, and the scientific and technological talents should bear the income decline caused by less efforts.

\subsection{Loss bearing mechanism}

At the same time of profit sharing, scientific and technological talents should share the losses of the hightech enterprise with the owners of material capital, and compensate with property. However, due to the lack of investment in currency and real assets when scientific and technological talents become shareholders, this has brought obstacles to the burden of losses. When losses occur, technical talents have no assets remaining in the enterprise to make up for them. To solve the above problems, the following methods can be adopted. When the surplus reserve is withdrawn, the part of the surplus reserve that belongs to the human capital of scientific and technological talents should be withdrawn in the early stage. After the share of human capital has been fully raised, it shall be withdrawn in the same proportion as the physical capital. The surplus reserve that has been withdrawn more shall be used as the fund to compensate the loss of the enterprise and bear the limited liability in the bankruptcy liquidation. 


\section{The design of human capital exit mechanism of science and technology talents in high-tech industry}

If the scientific and technological talents choose to withdraw from the high-tech enterprise, the human capital shares they hold shall be repurchased by the enterprise first, and the repurchasing price shall be determined by both parties through consultation. It is generally believed that the current market price of the stock should be selected as much as possible for the price of the buyback; at the same time, in order to eliminate the fluctuation of the stock price in the short term, the average price of the stock in the recent period can be adopted. After the buyback, the change registration of the decrease of the registered capital shall be handled. If the company abandons the buyback, it can transfer to others. In case of bankruptcy and liquidation of the company, material capital and human capital shareholders of science and technology talents shall bear limited liability to the company to the extent of their capital contribution.

\section{Acknowledgment}

Thanks for the support of Shandong science and Technology Department. Thanks for Xu Guojun's guidance.

Key research and development plan of Shandong Province (soft science) 2018RKC21002

\section{References}

1. Rongzheng consulting, statistics and analysis report on equity incentive of Listed Companies in 2019, Hexun, January 2020.

2. China Association of science and technology, national survey report of scientific and technological workers, China Science and Technology Press, 2018.

3. $\mathrm{Yu}$ Ao, Equity incentive of small and micro technological enterprises: an empirical interpretation, Journal of Sichuan University (philosophy and social sciences edition), March 2018.

4. Katsuhiro Motokawa, Human capital disclosure, accounting numbers, and share price, Journal of Financial Reporting and Accounting, October 2015. 